\title{
The Ultrastructure of Tricresylphosphate Poisoning in Primates 3. Studies on Alterations in Neuronal Soma
}

\author{
M. Mumtazuddin Ahmed \\ Department of Anatomy, College of Medicine and Medical Sciences, King Faisal University, \\ Dammam, Saudi Arabia
}

Received April 1, 1980

Summary. This report deals with the ultrastructural changes observed in neurons of the posterior root ganglion of slow loris (Nycticebus coucang) following administration of tricresylphosphate (TCP) $0.2 \mathrm{ml} / \mathrm{kg}$ body weight for 10 days. The observed changes involved the rough and smooth endoplasmic reticulum profiles, neurofilaments, Golgi complex as well as lipof uscin pigment. Nissl substance was markedly dispersed to the periphery of the neuron. Membranous profiles of the smooth endoplasmic reticulum were lost. Neurofilaments were markedly increased and manifested neurofibrillary tangles or else were scattered over the cytoplasm. Golgi complexes were dilated and there was a marked increase in lipof uscin.

These observations suggest that TCP produces degenerative changes in the organelles of sensory neurons similar to those seen at the height of chromatolysis produced by mechanical interference in the dorsal root ganglia and other neurons.

In earlier publications we reported the degenerative changes produced by tricresylphosphate (TCP) in the motor (AHMED and GLEEs, 1971) and sensory neurons of slow loris (Aнmed, 1972). These morphological changes were obtained by light microscopic studies. Recently a short communication was published showing some of our initial observations of neurotoxicity of TCP at a fine structural level in the sensory neurons (AHmED, 1973). The present paper will detail the ultrastructural alterations caused by TCP in posterior root ganglion cells of slow loris (Nycticebus coucang coucang), a feature which is not documented in primates.

\section{MATERIAL AND METHOD}

Six adult slow lorises were used in the experiments. In four of them a small area of skin at the back of the neck was shaved and $0.2 \mathrm{ml} / \mathrm{kg}$ body weight of TCP was painted on this area daily for 10 days, while 2 animals were used as control. All the 4 animals developed marked neurotoxic effects of TCP (AHmed and GLEes, 1971) within $8-10$ weeks. At the end of 10 weeks the animals were sacrificed and perfused with $6 \%$ glutaraldehyde and the posterior root ganglia were dissected out carefully. 
Small pieces of the ganglia were cut and post-fixed in 1\% osmic acid. After osmication the tissue was dehydrated and embedded in Araldite. U1trathin sections were cut, stained and examined under Hitachi HS8 electron microscope.

\section{RESULTS}

\section{Normal spinal ganglia (Fig. 1)}

In the spinal ganglia of the untreated lorises many of the features observed earlier (Aнмер, 1973) were confirmed. However, the control ganglion cells had large centrally placed nuclei with prominent and dark nucleoli. Sometimes two nucleoli were seen in a single nucleus. The ganglion cells contained a large number of Nissl substances scattered all over the cytoplasm especially in the perinuclear regions leaving the peripheral part of the soma somewhat free from such aggregates. The Nissl substance was made up of aggregates of rough surface cisterns of endoplasmic reticulum and clusters of free ribosomes. Neurofilaments were located throughout the cell but they were well-marked between the Nissl aggregates. Mitochondria were of fairly uniform size with a moderately dense matrix and cristae. The Golgi complex with its typical structure and few dense bodies were also noted in the perikaryon.

\section{Changes in the toxic neurons}

The nucleus was usually seen displaced from its central position towards the peri-

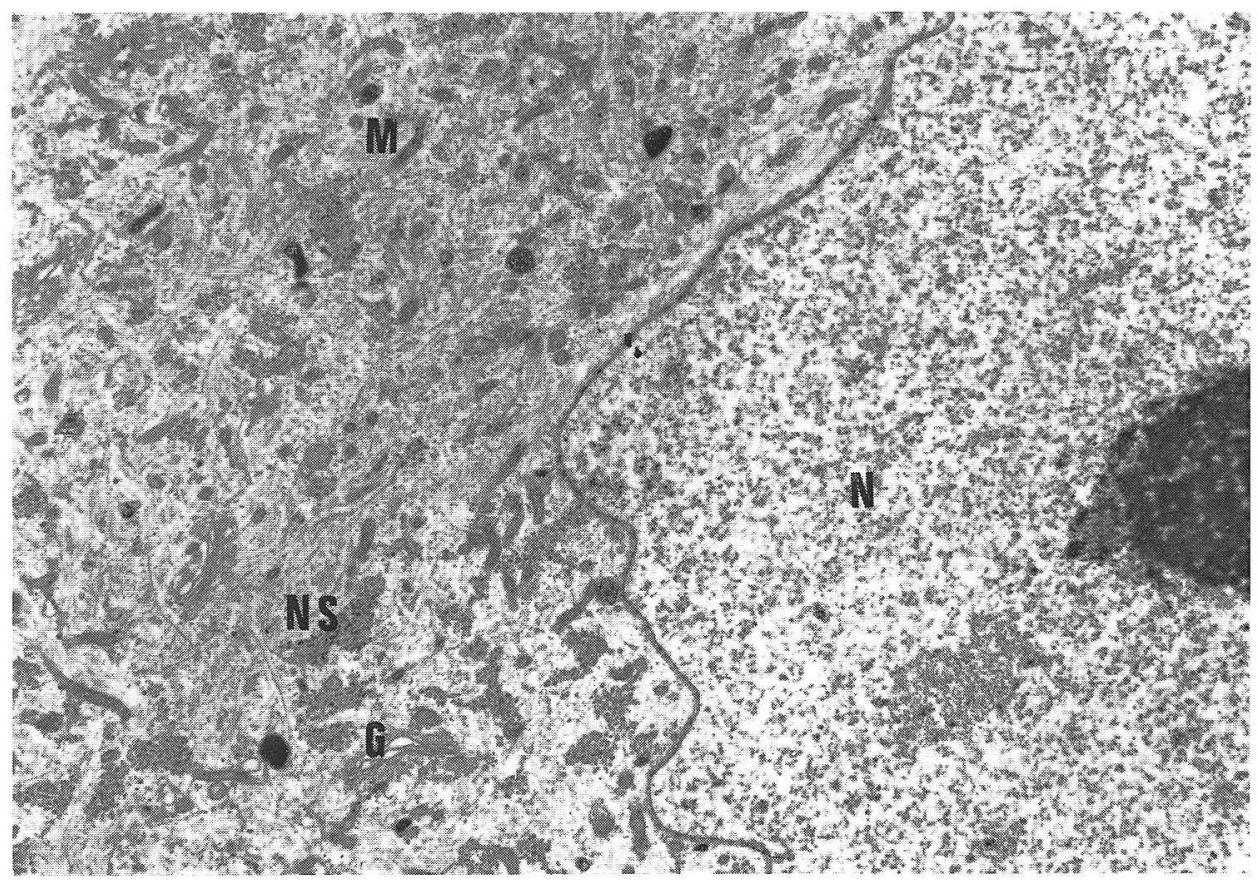

Fig. 1. Neuron from control slow loris showing nucleus $(N)$, Nissl substance (NS), mitochondria $(M)$, Golgi complex $(G)$ and neurofilaments. $\quad \times 8,100$ 


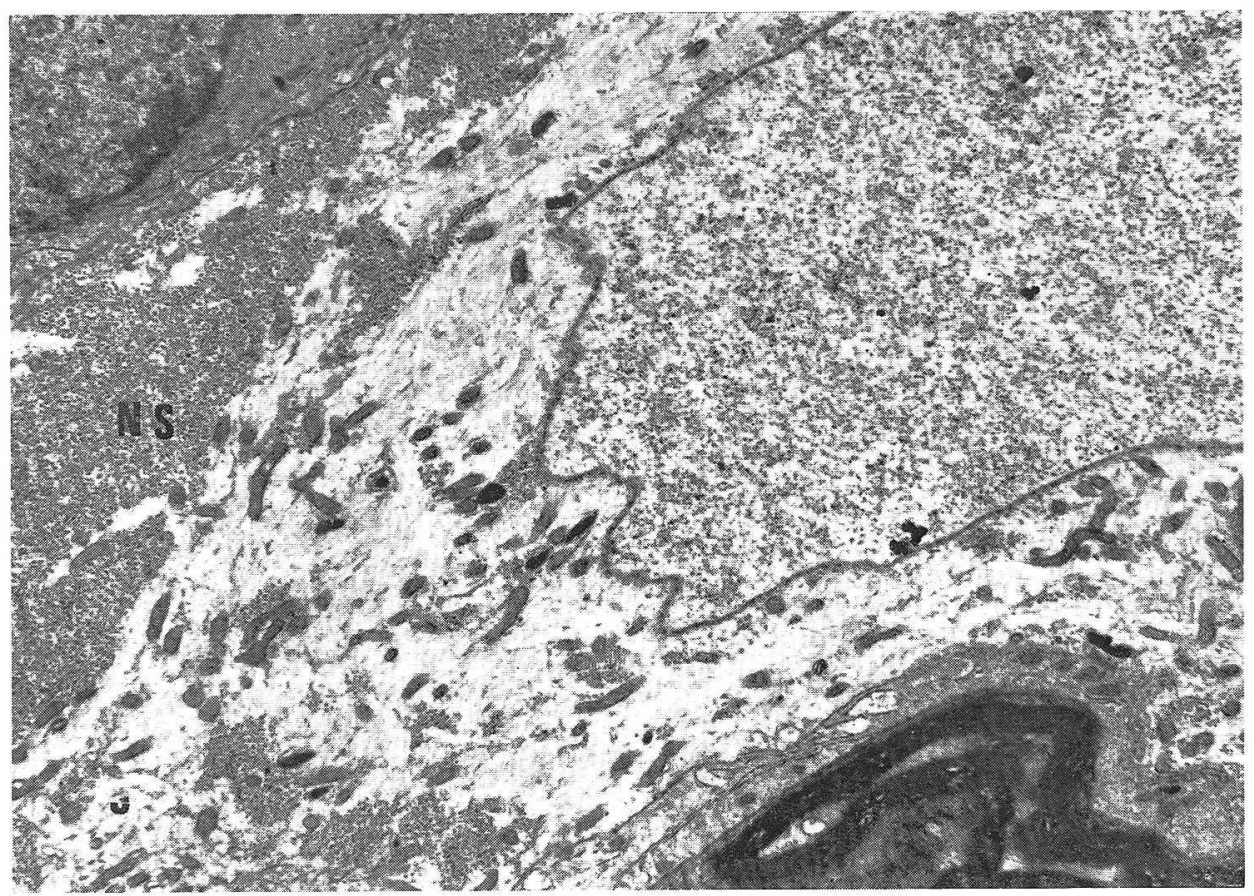

Fig. 2. Chromatolytic neuron following TCP poisoning. Note the peripheral dispersion of Nissl substance (NS) leaving the perinuclear region somewhat free from such aggregates (compare Fig. 1) $\times 8,100$

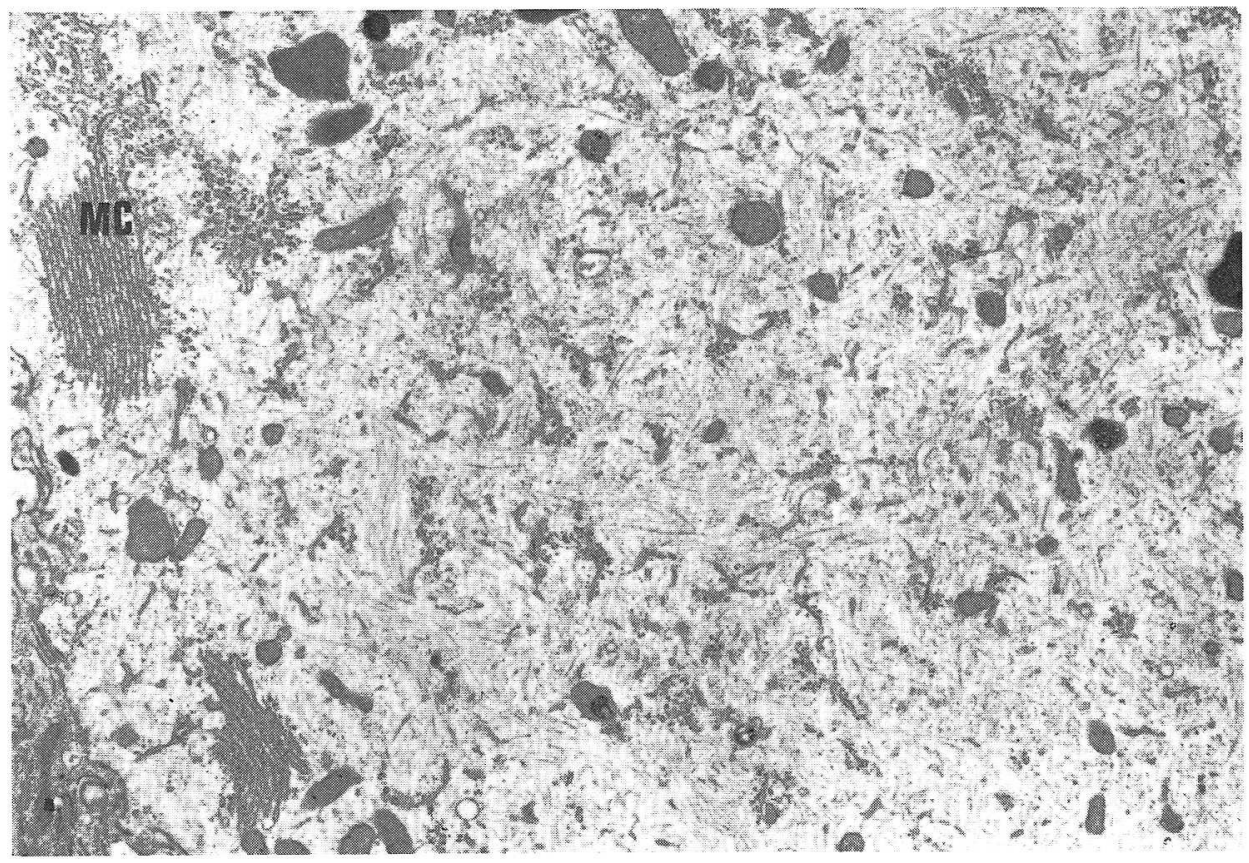

Fig. 3. Toxic neuron at the height of chromatolysis exhibiting overall loss of Nissl substance and membranous component of granular endoplasmic reticulum (compare Fig. 1). Note an unusual membrane complex $(M C)$ in the peripheral part of the soma. $\times 11,500$ 
pheral part of the perikaryon. Unlike the control cells, many neurons showed marked peripheral displacement of Nissl substance leaving the perinuclear region somewhat free from such aggregates (Fig. 2). In general there was a loss of membranous components of the Nissl substance and dispersion of free ribosomes all over the perikaryon (Fig. 3). A few of these cells also contained some unusual tubular membrane complexes with electron-dense particles in them (Fig. 3). Cells with vacuolated or swollen mitochondria were also observed (AHMED and GleEs, 1977).

Another striking feature in the perikaryon of most of the affected neurons was the presence of large numbers of neurotubules (Fig. 4) and neurofilaments. In some cells the filaments were seen in the form of neurofibrillary tangles with some electron deposits (Fig. 5), whereas in others the entire cell was filled up by the neurofilaments (Fig. 6). Cytoplasmic dense and lipofuscin bodies of various sizes, shapes and internal structures were also encountered in most of the experimental cells

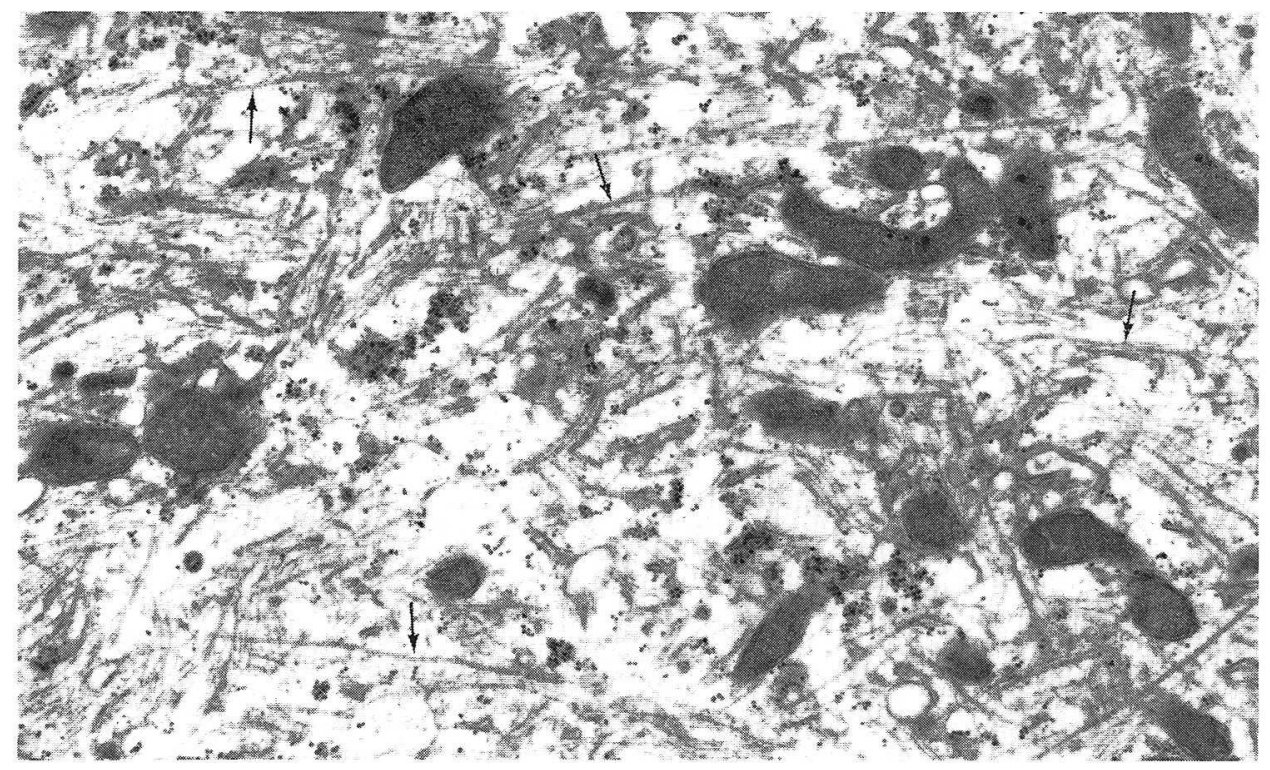

Fig. 4. Portion of neuronal soma showing large number of microtubules $(\uparrow)$ and dense mitochondria. $\times 19,000$

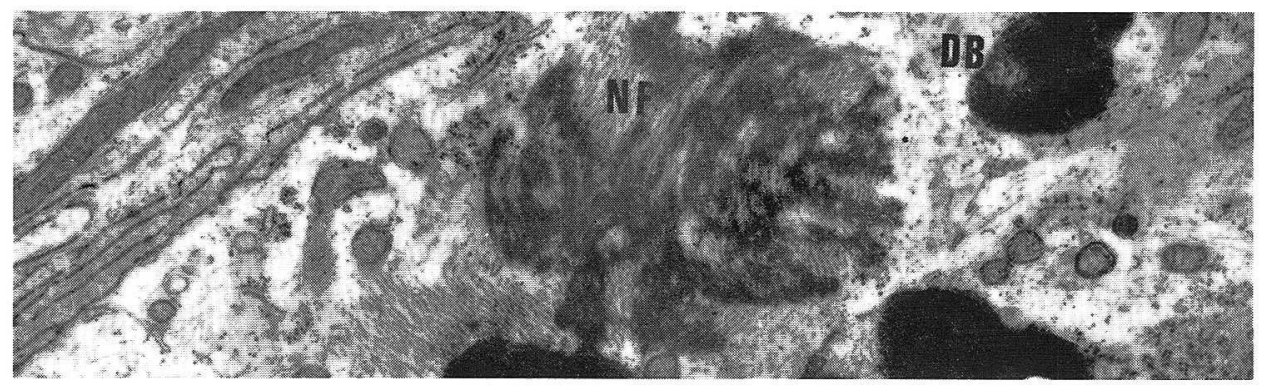

Fig. 5. Neurofibrillary tangles $(N F)$ in the soma of toxic neurons. Note the dense bodies $(D B)$. $\times 29,000$ 


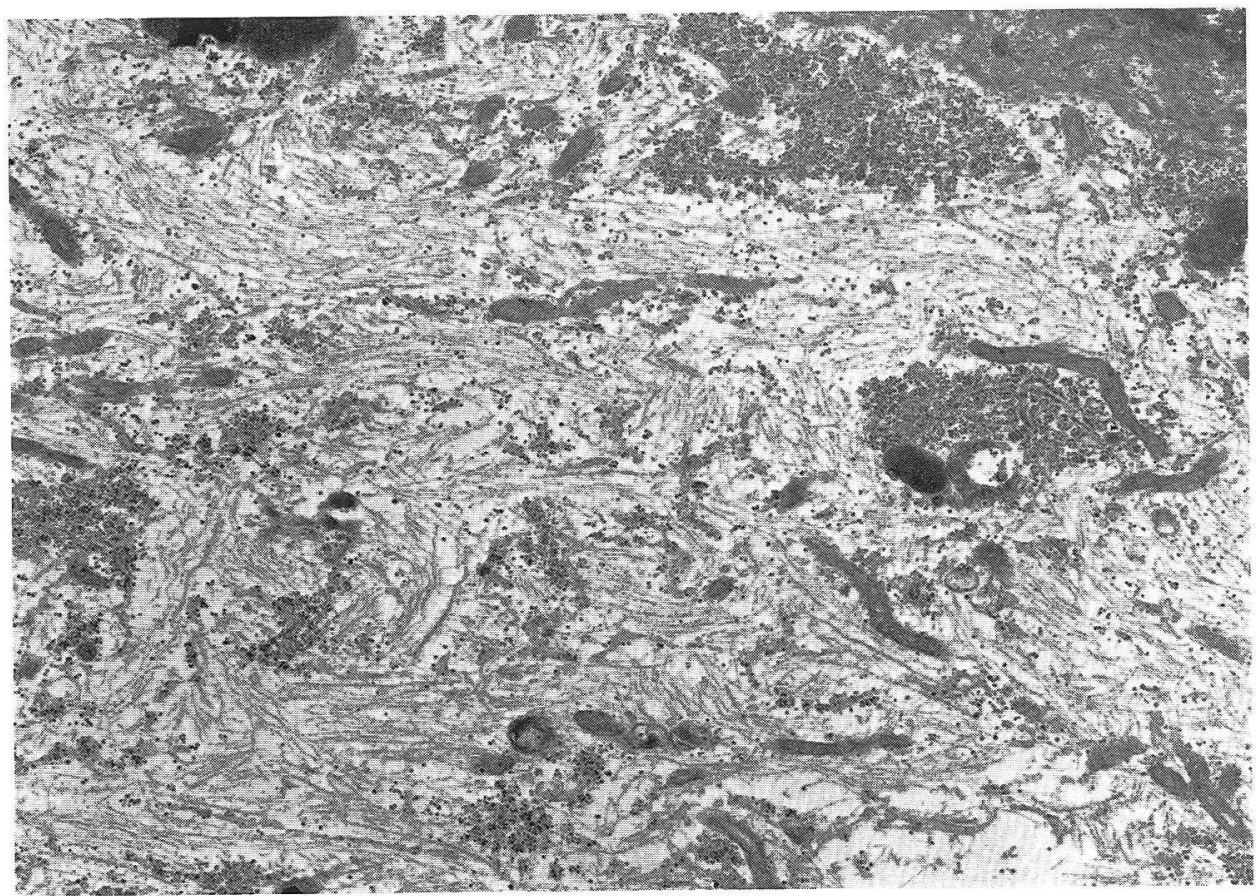

Fig. 6. Toxic neuron exhibiting extensive neurofilamentous hypertrophy. $\times 17,300$

(Fig. 7). The detailed description of these bodies has already been reported (AHmED and GleEs, 1977). Few of the toxic neurons showed an increase in the number of Golgi complexes, while in others there was a marked dilatation of Golgi vacuoles and smooth endoplasmic reticulum (Fig. 8).

\section{DISCUSSION}

Unlike in control animals, in the experimental material, the Nissl substance was seen mainly in the peripheral part of the perikaryon. This finding not only confirms our light microscopic observations (Aнmed, 1972) but also is in line with the phenomenon of chromatolysis caused by mechanical interference in the posterior root ganglia (Mackay et al., 1964; Lieberman, 1971; Nathaniel, 1971). There was also an overall loss and transformation of ribosomal rosettes into free ribosomes in most of the cells. Similar changes were also seen after axon section and repcrted to be a "true degenerative phenomenon of the cell" (TORvik et al., 1971; Torvik, 1972). In the present study, however, there was in addition to the dispersion of ribosomal rosettes into single elements, a disappearance of membrane components of granular endoplasmic reticulum. These alterations indicate the involvement of the neuronal perikaryon in TCP intoxication and especially the mechanism of protein synthesis.

Common to most of the affected neurons was a striking increase of neurofilaments and neurotubules in their cytoplasm. Similar increases in the number of neurofilaments were reported in sensory and motor neurons following axon sections 


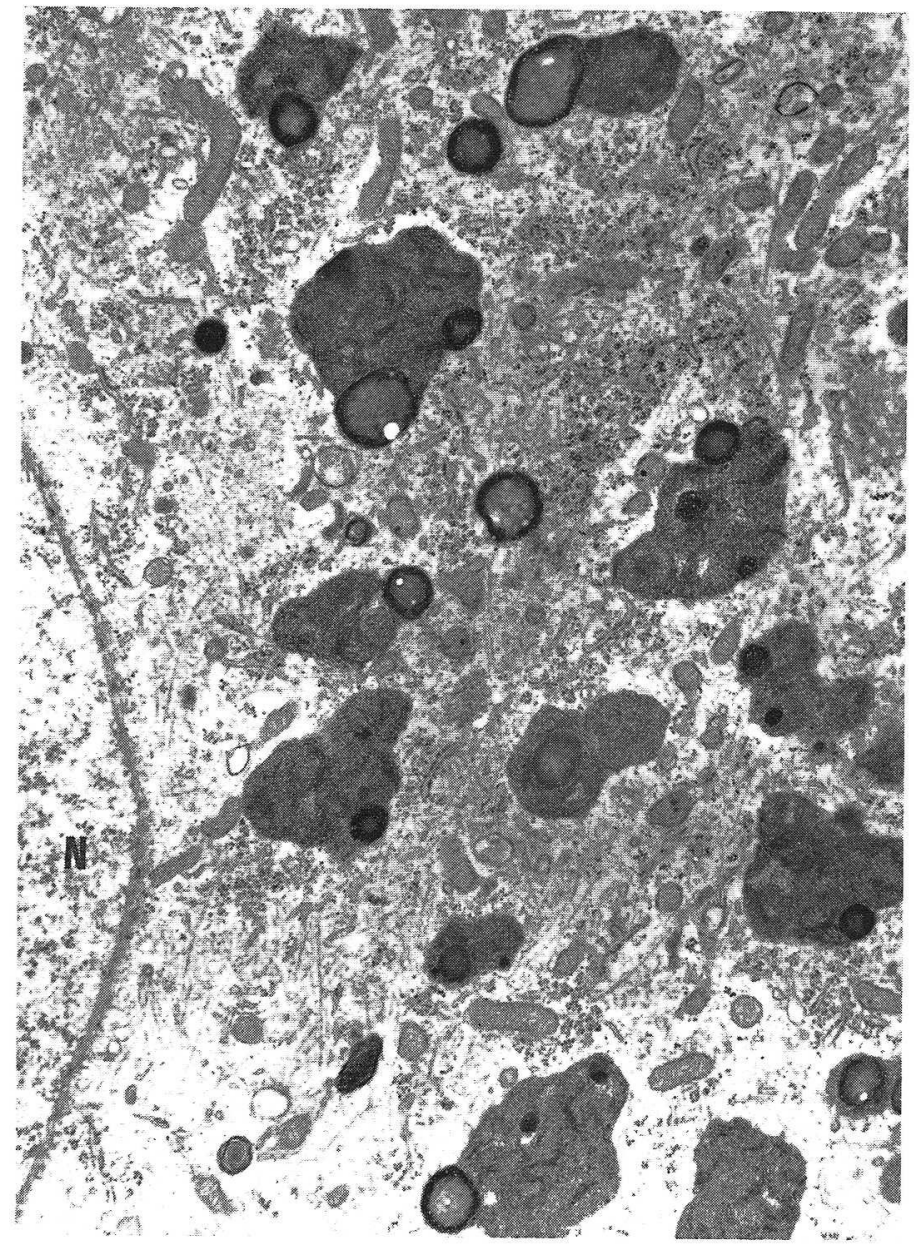

Fig. 7. Portion of nucleus $(N)$, and cytoplasm from toxic neuron showing large collection of lipofuscin bodies of various sizes and shapes. $\times 19,000$

(Evans et al., 1961.; Prineas, 1969; Barron et al., 1970, 1971). It was stated that a significant increase in the number of neurofilaments in the neuronal cytoplasm subjected to axon section were signs of degeneration and cell death (Torvik et al., 1971; Torvik, 1972). The exact mechanism by which a large number of neurofilaments are produced is not known. At least two possible explanations are proposed: cytoplasmic stasis (CHou et al., 1965) and cell injury (SEIL et al., 1968). In TCP poisoning in birds there is a peripheral as well as central neuronal degeneration and formation of large number of intracytoplasmic neurofilaments (AHMED, 1970; LE VAy et al., 1971). Therefore, it is concluded that under the toxic action of TCP, a large number of neurofilaments are produced in the experimental neurons. However, the biochemical steps by which TCP induces the formation of large number of intraneuronal filaments and their probable transformation into neurotubules is still unknown.

The appearance of large numbers of lipofuscin bodies and dilatation of the Golgi complex may be a reactive phenomenon to meet the increased demand for enzymes to catabolize the products of neuronal degeneration. 


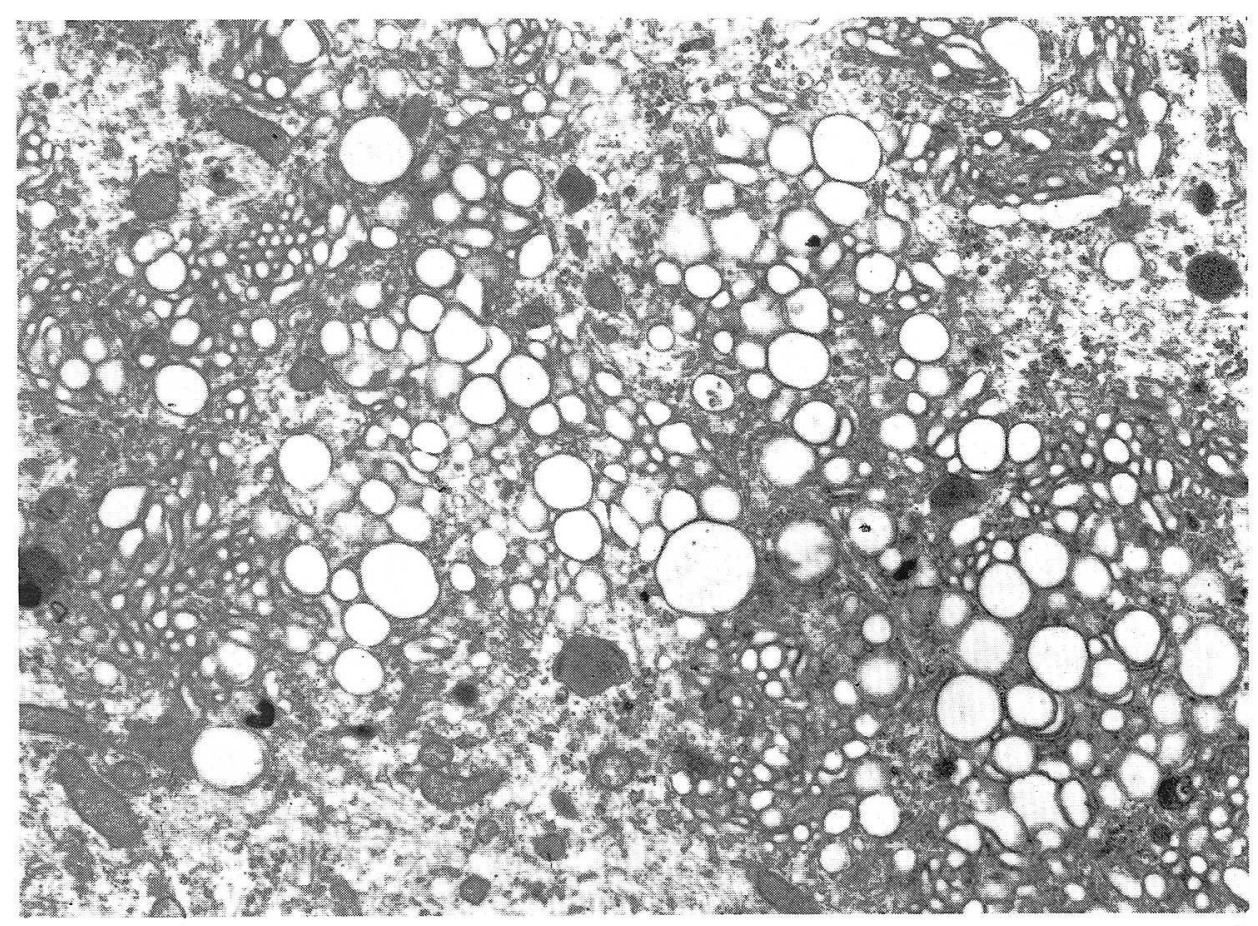

Fig. 8. Cytoplasmic area from toxic neuron showing markedly dilated Golgi complex and smooth ER. $\times 15,400$

Finally, the results presented in this investigation provide support at a fine structural level to the hypothesis that the toxic effects of TCP are not only seen in the nerve fibers (Ahmed, 1973), and motor neurons (Ahmed and Glees, 1971), but are also manifested in the various organelles in the perikaryon of sensory neurons. However, the mechanism by which TCP leads to the structural changes remains unclear. At present, it is not known whether the primary site of action involves the protein synthesis or the metabolic pathway. The observed structural changes may be secondary manifestations of some such primary action of TCP, a point requires further experimental studies in primates.

Acknowledgement. I wish to thank Professor Adel Afrfi, American University of Beruit, for his valuable suggestions and for correcting the manuscript. The technical assistance of Mr. Tajuddin b. M. Ali, Mr. P. Gopal and Mr. Ali Ahmad Maнвоoв is gratefully acknowledged.

\section{REFERENCES}

Ahmed, M. Mumtazuddin: A note on the neuroglia in normal and tricresylphosphate (TCP) poisoned hen. Acta anat. 77: 120-130 (1970).

-: A note on the toxic effects of tricresylphosphate on spinal ganglion of slow loris (Nycticebus coucang coucang). Anat. Anz. 131: 476-480 (1972).

-: The ultrastructure of tricresylphosphate poisoning in primates. 1. Studies on axonal alterations in the spinal cord. Arch. histol. jap. 35: 283-288 (1973).

: Ultrastructural changes in sensory ganglion cells due to tricresylphosphate poisoning in 
primates. Int. Res. Commun. System (73/11): 10-14 (1973).

Ahmed M, Mumtazuddin : Fine structure of spinal ganglia in slow loris. Arch. histol. jap. 36: 143-152 (1973).

Ahmed, M. Mumtazuddin and P. Glees: Neurotoxicity of tricresylphosphate (TCP) in slow loris (Nycticebus coucang coucang). Acta neuropathol. 19: 94-98 (1971).

- : Mitochondrial degeneration after organic phosphate poisoning in Prosimian primates. Cell Tiss. Res. 175: 459-465 (1977).

Barron, K. D., A. C. Daniels, T. Y. Chiang and P. F. Doolin: Fine structure of chromatolytic feline motoneurons. Exp. molec. Pathol. 12: 46-57 (1970).

Barron, K. D., T. Y. Chiang, A. C. Daniels and P. F. Doolin: Subcellular accompaniments of axon reaction in cervical motoneurons of the cat. In: (ed. by) H. M. Zimmerman: Progress in neuropathology. Grune and Stratton, New York, 1971 (Vol 1, p. 255-280)

Chou, S. M. and H. A. Hartmann : Electron microscopy of focal neuroaxonal lesions produced by B-B'-iminodipropionitrile (IDPN) in rats. I. The advanced lesions. Acta neuropathol. 4: 590-603 (1965).

Evans, D. H. L. and E. G. Gray : Changes in the fine structure of ganglion cells during chromatolysis. In: Cytology of nervous tissue (Proc. Anat. Soc. Great Brit. Ireland). Taylor and Francis, London, 1961. (p. 71-74).

Le Vay, S., C. Meier and P. Glees: Effects of tri-ortho-cresyl-phosphate on spinal ganglia and peripheral nerves of chicken. Acta neuropathol. 17: 103-113 (1971).

Lieberman, A. R.: The axon reaction: A review of the principal features of perikaryal responses to axon injury. Int. Rev. Neurobiol. 14: 49-124 (1971).

Mackay, E. A., D. Spiro and J. Wiener: A study of chromatolysis in dorsal root ganglia at the cellular level. J. Neuropathol. exp. Neurol. 23: 508-526 (1964).

Nathaniel,E. J. H.: Fine structural changes in spinal ganglion and satellite cells following crush lesions of dorsal roots in adult rats. Anat. Rec. 169: 385-386 (1971).

Prineas, J.: The pathogenesis of dying-back polyneuropathies. Part I. An ultrastructural study of experimental tri-ortho-cresyl phosphate intoxication in the cat. J. Neuropathol. exp. Neurol. 28: 571-597 (1969).

Seil, F. J., and P. W. Lampert: Neurofibrillary tangles induced by vincristine and vinblastine sulfate in central and peripheral neurons in vitro. Exp. Neurol. 21: 219-230 (1968).

Torvik, A.: Phagocytosis of nerve cells during retrograde degeneration. An electron microscopic study. J. Neuropathol. exp. Neurol. 31: 132-146 (1972).

Torvik, A. and F. Skjorten: Electron microscopic observations on nerve cell regeneration and degeneration after axon lesions. 1. Changes in the nerve cell cytoplasm. Acta neuropathol. 17: 248-264 (1971).

Dr. M. Mumtazuddin Ahmed

Department of Anatomy

College of Medicine and Medical Sciences

King Faisal University

Dammam, Saudi Arabia 